\title{
Mechanism, frequency, transfusion and outcome of severe trauma in coagulopathic paediatric patients
}

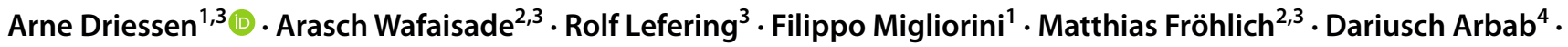 \\ Marc Maegele $^{2,3} \cdot$ Manuel Mutschler ${ }^{2,3,5}$
}

Received: 8 November 2019 / Accepted: 16 May 2020 / Published online: 24 May 2020

(c) The Author(s) 2020

\begin{abstract}
Purpose Acute traumatic coagulopathy can result in uncontrolled haemorrhage responsible for the majority of early deaths after adult trauma. Data on the frequency, transfusion practice and outcome of severe trauma haemorrhage in paediatric patients are inconsistent.

Methods Datasets from paediatric trauma patients were retrieved from the registry of the German trauma society (TR-DGU $\left.{ }^{\circledR}\right)$ between 2009 and 2016. Coagulopathy was defined by a Quick's value $<70 \%$ (INR (international normalized ratio) $>1.4$ ) and/or thrombocytes $\leq 100 \mathrm{k}$ upon emergency room admission. Children were grouped according to age in 4 different groups (A: 1-5, B: 6-10, C: 11-15 and D: 16-17 years). Prevalence of coagulopathy was assessed. Demographics, injury severity, haemostatic management including transfusions and mortality were described.

Results 5351 primary admitted children $\leq 17$ years with an abbreviated injury scale (AIS) $\geq 3$ and complete datasets were included. The prevalence of coagulopathy was $13.7 \%$ (733/5351). The majority of the children sustained blunt trauma (more than $90 \%$ independent of age group) and a combination of traumatic brain injury (TBI) and any other trauma in more than $60 \%$ (A, C, D) and in 53.8\% in group B. Coagulopathy occurred the most among the youngest (A: $18.2 \%$ ), followed by all other age groups with approximately $13 \%$. Overall mortality was the highest in the youngest (A: $40.9 \%$ ) and among the youngest patients with traumatic brain injury (A: $71.4 \%$ and B: $47.1 \%$ ). Transfusion of packed red blood cells (pRBCs) and fresh frozen plasma (FFPs) occurred almost in a 2:1 ratio (or less) across all age subgroups.

Conclusion Traumatic haemorrhage in association with coagulopathy and severe shock is a major challenge in paediatric trauma across all age groups.
\end{abstract}

Keywords Coagulopathy $\cdot$ Haemorrhage $\cdot$ Paediatric trauma $\cdot$ Transfusion $\cdot$ Mortality

\section{Abbreviations}

AIS Abbreviated Injury Scale

ATC Acute traumatic coagulopathy

BE Base excess

Electronic supplementary material The online version of this article (https://doi.org/10.1007/s00068-020-01398-x) contains supplementary material, which is available to authorized users.

Arne Driessen

adriessen@ukaachen.de

1 Department of Orthopaedic Surgery, University Hospital RWTH Aachen, RWTH Aachen University, Pauwelsstraße 30, 52074 Aachen, Germany

2 Department of Orthopaedic Surgery, Trauma Surgery and Sports Traumatology, University of Witten/Herdecke, Cologne-Merheim Medical Centre (CMMC), Cologne, Germany
BP Blood pressure

ChiCo Children in coagulopathy

DGU Deutsche Gesellschaft für Unfallchirurgie (German Trauma Society)

ED Emergency department

FFP Fresh frozen plasma

GCS Glasgow Coma Scale
3 Institute for Research in Operative Medicine (IFOM), University of Witten/Herdecke, Cologne Merheim Medical Centre (CMMC), Cologne, Germany

4 Department of Orthopaedic Surgery, Klinikum Dortmund, Dortmund, Germany

5 Department of Foot and Ankle Surgery, Johanniter Waldkrankenhaus Bonn, Bonn, Germany 


$\begin{array}{ll}\text { ICU } & \text { Intensive care unit } \\ \text { INR } & \text { International normalized ratio } \\ \text { ISS } & \text { Injury Severity Score } \\ \text { MOF } & \text { Multiple organ failure } \\ \text { MTP } & \text { Massive transfusion protocol } \\ \text { NISS } & \text { New Injury Severity Score } \\ \text { PH } & \text { Prehospital } \\ \text { pRBC } & \text { Packed red blood cells } \\ \text { PTr } & \text { Prothrombin time ratio } \\ \text { PTT } & \text { Partial thromboplastin time } \\ \text { RISC } & \text { Revised Injury Severity Classification } \\ \text { SOFA } & \text { Sequential organ failure assessment } \\ \text { TASH } & \text { Trauma-Associated Severe Haemorrhage Score }\end{array}$

\section{Background}

Trauma is the leading cause of death in persons aged 1-44 years [1] and accounts for approximately $10 \%$ of all deaths in this group [2]. Despite substantial improvements in acute trauma care over the past decades, uncontrolled haemorrhage is still responsible for approximately $50 \%$ of all traumarelated deaths within the first $48 \mathrm{~h}$ after hospital admission [3, 4]. Meanwhile, a new appreciation of coagulopathy in acute trauma care has evolved and the acute traumatic coagulopathy (ATC) is now recognized as an own entity [5-7]. To date, six key initiators of ATC have been ascribed: tissue trauma, shock, haemodilution, hypothermia, acidemia, and inflammation [8]. Brohi et al. [9] emphasized the role of hypoperfusion and shock for the initiation of ATC. In adult trauma patients, frequencies for ATC upon emergency room (ER) admission have been reported to range between 20 and $60 \%$ according to definition $[5,10,11]$. However, data on the incidence for coagulopathy and shock in the paediatric population with predominantly blunt injury are rare. One large report including both shock and coagulopathy measures has been published for children with mostly penetrating injury [12]. Hendrickson and colleagues have evaluated coagulopathy in a single centre cohort of 102 children with $>80 \%$ blunt injuries on ER presentation and quantified the relationship with mortality [13]. We report on the frequency of coagulopathy upon ER admission in children ( $\leq 17$ years) with predominantly blunt injury, subsequent on transfusion practice in cases of severe trauma haemorrhage and on outcome based upon data derived from the trauma registry of the Deutsche Gesellschaft für Unfallchirurgie (German Trauma Society/TR-DGU ${ }^{\circledR}$ ).

\section{Methods}

Over 230,000 trauma patients that have been entered into the TR-DGU ${ }^{\circledR}$ database between 2009 and 2016 were reviewed. 733 datasets from children aged 1-17 years were identified for further analysis (Fig. 1). All children had sustained significant trauma (Abbreviated injury Scale-AIS $\geq 3$ ), had been primarily admitted and had a complete dataset for Quick's value [prothrombin time ratio (PTr)], PTT (partial thromboplastin time) and number of thrombocytes upon ER admission. For further analysis, this population was divided into four subgroups according to age: group A: age 1-5, group B: age 6-10, and group C: age $11-15$ and group D: age 16-17 years. Subgroups were compared to control group E age 18-54 $(n=5793)$.

\section{The TR-DGU ${ }^{\circledR}$ (Trauma Register-Deutsche Gesellschaft für Unfallchirurgie)}

The TR-DGU ${ }^{\circledR}$ was founded in 1993 by the German Trauma Society [14]. It is a prospective, multicentre, standardized and pseudonymous documentation of multiple injured trauma patients at four consecutive post-trauma phases from initial injury to hospital discharge: (1) the pre-hospital phase; (2) emergency room and initial surgery; (3) intensive care unit (ICU) and (4) outcome status at discharge and description of injuries and procedures. Detailed information on demographics, injury pattern, co-morbidities, pre-hospital and early in-hospital management, time course, relevant

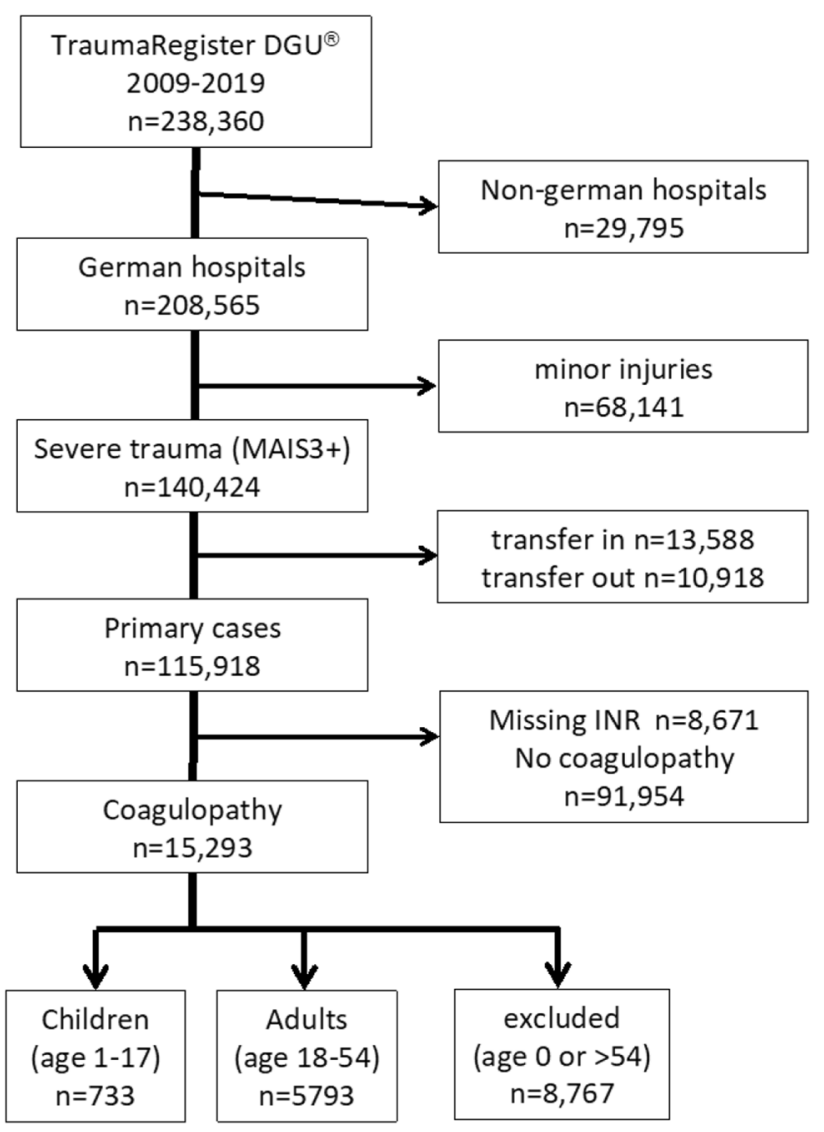

Fig. 1 Flowchart of patient selection according to the eligibility criteria 
laboratory findings, and outcome of each individual are captured. Between 2009 and 2016, over 50,000 patients from more than 400 hospitals had been entered into the database. All injuries are coded using the Abbreviated Injury Scale (AIS) [15]. Scientific data analysis is approved according to a peer-review procedure laid down in the publication guideline of TR-DGU ${ }^{\circledR}$.

The present study is in line with the publication guidelines of the TR-DGU ${ }^{\circledR}$ and registered as TR-DGU project ID 2018-005.

All methods were carried out in accordance with relevant guidelines and regulations. More information can be found online under https://www.traumaregister-dgu.de.

\section{Definition of coagulopathy and magnitude of trauma haemorrhage}

Coagulopathy was defined by the presence of a Quick's value (prothrombin time ratio/PTr) $<70 \%$ upon ER admission [16]. The prothrombin time test was first introduced by A. J. Quick in 1935 and is either expressed in Quick-\% $(70-130 \%=$ normal $)$ or as a prothrombin time ratio $(\mathrm{PTr})$ [16]. Although the international normalized ratio (INR) was introduced as a coagulation test, most German physicians and medical institutions prefer the prothrombin time in Quick (\%). Thus, the TR-DGU ${ }^{\circledR}$ documents prothrombin time in Quick-\%. A Quick's value of $<70 \%$ is equivalent to an INR (international normalized ratio) of approximately 1.4. Coagulopathy was distinguished via laboratory findings: Quick's value $<70 \%$ (INR $>1.4$ ) or PTT $\geq 40$ or thrombocyte count of $\leq 100,000$. Demographics, injury severity, haemostatic management including volume administration and transfusions and outcome were assessed in all groups.

\section{Statistical analysis}

All data were analysed by SPSS statistical software (version 24, IBM Inc., Armonk, NY). Clinical data were compared using the $\mathrm{Chi}^{2}$-test for categorical variables and the Mann-Whitney $U$ test for continuous variables. A $P$ value $<0.05$ was considered significant.

\section{Results}

A total of 238,360 patient recordings entered into the TRDGU $^{\circledR}$ between 2009 and 2016 were identified for further analysis. Coagulopathy upon Emergency Department (ED) admission was present in 733 out of 5351 (13.7\%) children matching the criteria (Fig. 1).

The vast majority of injured children were male with increasing percentage in the higher age groups (A: 57.3\%; B: 61.5\%; C: 71.1\%; D: 74.7\%). Furthermore, in all age groups well above $90 \%$ of children suffered injuries caused by blunt trauma. The majority of elderly children in group D suffered traffic related injuries in motorcycle accidents (37.0\%) and car accidents (25.7\%). Likewise, the majority of children in other age groups suffered injuries caused by car accidents (A: $23.8 \%$; B: $27.8 \%$; $: 22.3 \%$ ) followed by bicycle injuries (especially group C: $20.8 \%$ and B: $12.2 \%$ ). More than $21 \%$ of the youngest children (group A) were injured by high falls (>3 m) followed by $17.8 \%$ (group C), $11.3 \%$ (group D) and $9.6 \%$ (group B). Demographics and trauma mechanism according to the age groups of children in coagulopathy are depicted in Table 1.

\section{Injury severity and injury pattern}

When compared to all trauma patients (E: 51.8\%) recorded in the TR-DGU ${ }^{\circledR}$, the AIS head in all age groups is the highest in the youngest (A: 80\%) decreasing in other age groups to the oldest in group D (55.8\%) (Table 2). In contrast, the percentage of patients with thoracic injuries (A: $38.3 \%$ to D: $63.1 \%$ ) and extremity injuries (A: $20.9 \%$ to D: $53.8 \%$ ) is increasing steadily with growing age reaching almost the average percentage of the control group. More than $50 \%$ of the patients aged between 1 and 10 years suffered a monotrauma but only $19.2 \%$ of group A and $14.5 \%$ of group B suffered an isolated brain injury. Over $60 \%$ of the patients in age group A, C and D and over 50\% in group B suffered a combined trauma (head plus other body region).

\section{Coagulopathy}

Within the age groups, coagulopathy occurred the most among the youngest (A: 18.2\%), followed by all other age groups with approximately $13 \%$. The mean INR for children in group A was $1.92( \pm 1.25)$, group B $1.82( \pm 1.24)$, group C $1.79( \pm 0.87)$, group D $2.07( \pm 1.66)$ and control group 1.92 $( \pm 1.35)$. A total of 733 children presented with a Quick's value $<70 \%$ (INR $>1.4$ ) or PTT $\geq 40$ or thrombocyte count of $\leq 100,000$ (Table 3 ). The majority of these children can be found among the youngest (A: $57.3 \%, n=63$ ). Groups B-D are depicted in Table 3.

\section{Management}

The length of hospital stay (days) is increasing with age (A: 14.1, B: 14.8, C: 17.2, D: 18.9) as well as the time on ICU (A: 8.0, B: 8.0, C: 8.7, D: 10.7) and quantity of days patients depend on mechanical ventilation (A: 4.5, B: 4.4, C: 4.6, D: 6.3). Transfusion requirements until ICU admission and volume administration during the prehospital resuscitation and in the ED are depicted in Figs. 2 and 3. The total amount was the smallest in the youngest and decreases with age reflecting an age (and body weight)-based volume substitution. 
Table 1 Demographics and injury pattern of children admitted to the emergency department (ED) in the state of coagulopathy according to different age groups

\begin{tabular}{llllll}
\hline Age group & A (1-5 years) & B (6-10 years) & C (11-15 years) & D (16-17 years) & E control \\
\hline $\begin{array}{l}\text { Children with } \\
\text { coagulopathy }\end{array}$ & $n=110$ & $n=117$ & $n=205$ & $n=301$ & $n=5793$ \\
$\quad$ ChiCo) & $733 / 5351(13.7 \%)$ & & & \\
$\begin{array}{l}\text { Male sex } \\
\text { Mechanism of trauma }\end{array}$ & $57.3 \%(63)$ & $61.5 \%(72)$ & $71.1 \%(145)$ & $74.7 \%(224)$ & $75.9 \%(4369)$ \\
$\quad$ Blunt trauma & $97.0 \%(98)$ & $94.7 \%(107)$ & $93.5 \%(187)$ & $92.3 \%(262)$ & $92.2 \%(5094)$ \\
Cause of injury & & & & \\
Car accident & $23.8 \%(25)$ & $27.8 \%(32)$ & $22.3 \%(45)$ & $25.7 \%(75)$ & $32.8 \%(1864)$ \\
Motorbike & $0 \%(0)$ & $0.9 \%(1)$ & $5.9 \%(12)$ & $37 \%(108)$ & $18.9 \%(1076)$ \\
Bicycle & $1.9 \%(2)$ & $12.2 \%(14)$ & $20.8 \%(42)$ & $4.5 \%(23)$ & $4.2 \%(283)$ \\
Pedestrian & $29.5 \%(31)$ & $31.3 \%(36)$ & $20.3 \%(41)$ & $8.2 \%(24)$ & $18.5 \%(132)$ \\
High fall (>3 m) & $21 \%(22)$ & $9.6 \%(11)$ & $17.8 \%(36)$ & $11.3 \%(33)$ & $18.4 \%(1044)$ \\
Low fall (<3 m) & $7.6 \%(8)$ & $4.3 \%(5)$ & $1.0 \%(2)$ & $0.3 \%(1)$ & $5.5 \%(310)$ \\
Others & $16.2 \%(17)$ & $13.9 \%(16)$ & $11.9 \%(24)$ & $13 \%(38)$ & $13.4 \%(762)$ \\
\hline
\end{tabular}

Table 2 Injury severity, injury pattern, hypotension and transfusion rate according to age groups

\begin{tabular}{|c|c|c|c|c|c|}
\hline Age group & A ( $1-5$ years $)$ & B (6-10 years) & $\mathrm{C}(11-15$ years $)$ & $\mathrm{D}(16-17$ years $)$ & E control \\
\hline Children with coagulopathy (ChiCo) & $\begin{array}{l}n=110 \\
733 / 5351(13.7 \%)\end{array}$ & $n=117$ & $n=205$ & $n=301$ & $n=5793$ \\
\hline \multicolumn{6}{|l|}{ Injury severity } \\
\hline GCS (mean) & $6.7(100)$ & $8.5(111)$ & $7.9(191)$ & $8.2(291)$ & $8.97(5506)$ \\
\hline ISS & $30.2(110)$ & $27.3(117)$ & $32.6(205)$ & $35.5(301)$ & $33.3(5793)$ \\
\hline \multicolumn{6}{|c|}{ Relevant injuries (Abbreviated Injury Scale (AIS) $>3$ ) (percent of total $\{n\}$ ) } \\
\hline AIS head & $80.0 \%(88)$ & $65.8 \%(77)$ & $68.8 \%(141)$ & $55.8 \%(168)$ & $51.8 \%(3001)$ \\
\hline AIS thorax & $38.3 \%(42)$ & $39.3 \%(46)$ & $58.5 \%(120)$ & $63.1 \%(190)$ & $64.8 \%(83,754)$ \\
\hline AIS abdomen & $14.5 \%(110)$ & $28.2 \%(33)$ & $24.9 \%(51)$ & $34.9 \%(105)$ & $30.0 \%(1736)$ \\
\hline AIS extremities & $20.9 \%(23)$ & $34.2 \%(40)$ & $37.6 \%(77)$ & $53.8 \%(162)$ & $50.6 \%(2930)$ \\
\hline \multicolumn{6}{|l|}{ Injury pattern } \\
\hline No head injury & $54.5 \%(60)$ & $51.3 \%(60)$ & $36.1 \%(74)$ & $31.6 \%(95)$ & $33.6 \%(1946)$ \\
\hline Isolated head injury & $19.2 \%(21)$ & $14.5 \%(17)$ & $7.3 \%(15)$ & $2.7 \%(8)$ & $6.3 \%(365)$ \\
\hline Combined trauma & $63.6 \%(70)$ & $53.8 \%(63)$ & $64.4 \%(132)$ & $60.5 \%(182)$ & $54.9 \%(3183)$ \\
\hline \multicolumn{6}{|l|}{ Transfusion rate } \\
\hline $\mathrm{pRBC}$ & $35.8 \%(39)$ & $30.8 \%(36)$ & $37.1(75)$ & $42.2 \%(125)$ & $44.8 \%(2574)$ \\
\hline FFP & $18.3 \%(20)$ & $18.8 \%(22)$ & $24.3 \%(49)$ & $29.4 \%(87)$ & $31 . \%(1805)$ \\
\hline \multicolumn{6}{|c|}{ Transfusion rate pRBCs without TBI (traumatic brain injury) } \\
\hline $\begin{array}{l}\text { pRBCs without TBI (\% of total in age } \\
\text { group) }(n)\end{array}$ & $37.1 \%(33 / 89)$ & $36 \%(36 / 100)$ & $29 \%(73 / 187)$ & $43.1(124 / 288)$ & $46.5 \%(2501 / 5382)$ \\
\hline
\end{tabular}

GCS Glasgow Coma Scale, ISS Injury Severity Score, $p R B C s$ packed red blood cells, $F F P$ fresh frozen plasma, $T B I$ traumatic brain injury)

On average and including those without transfusion, children in group A received less than one pRBC $(0.86 \pm 1.55)$ and FFP $(0.37 \pm 0.911)$, children in group $B$ received $1.4 \pm 3.26 \mathrm{pRBCs}$ and $0.89 \pm 2.59 \mathrm{FFP}$ rather reflecting a 2:1 transfusion rate. This ratio of pRBCs to FFP is converging to a more balanced administration in group C $(2.12 \pm 4.39-1.45 \pm 3.38)$ and $\mathrm{D}$
(3.01 $\pm 6.34-2.27 \pm 4.94)$. The overall transfusion rate for pRBCs and FFPs is the highest in group D $(42.2 \%, 29.4 \%)$ besides more than $30 \%$ for pRBCs and approximately $20 \%$ for FFPs in all other age groups (Table 2). As expected, transfusion rates of pRBCs were lower and independent of age in the groups having sustained only TBI than in those having sustained any other injury but TBI. 
Table 3 Outcome and mortality depending on injury pattern of children admitted to the ED (emergency department)

\begin{tabular}{|c|c|c|c|c|c|}
\hline Age group & A (1-5 years) & B (6-10 years) & $\mathrm{C}(11-15$ years $)$ & D (16-17 years) & E control \\
\hline & $733 / 5351(13.7 \%)$ & & & & \\
\hline Children with coagulopathy (\% per group) & $18.2 \%(n=110)$ & $13.4 \%(n=117)$ & $12.7 \%(n=205)$ & $13.3 \%(n=301)$ & $10.9 \%(n=5793)$ \\
\hline \multicolumn{6}{|l|}{ Hospital stay } \\
\hline Length of hospital stay (days) & 14.1 (SD 14.7) & 14.8 (SD15.0) & $17.2($ SD 20.9) & 18.9 (SD 18.6) & $22.6(\mathrm{SD} 25.1)$ \\
\hline ICU stay (days) & $8.0($ SD 11.2) & $8.0(\mathrm{SD} 13.1)$ & 8.7 (SD 10.6) & 10.7 (SD 13.6) & 11.4 (SD 14.7) \\
\hline Ventilator time (days) & $4.5(\mathrm{SD} 2.0)$ & $4.42(\mathrm{SD} 8.1)$ & $4.6(\mathrm{SD} 6.7)$ & $6.3(\mathrm{SD} 10.5)$ & $6.8(\mathrm{SD} 11.2)$ \\
\hline \multicolumn{6}{|l|}{ Overall outcome (percent of total $\{n\}$ ) } \\
\hline Overall mortality & $40.9 \%(45)$ & $29.1 \%(34)$ & $33.2 \%(68)$ & $31.9 \%(96)$ & $32.2 \%(1867)$ \\
\hline Mortality with TBI & $48.9 \%(43 / 88)$ & $41.6 \%(32 / 77)$ & $43.3 \%(61 / 141)$ & $46.4 \%(78 / 168)$ & $47.4 \%(1421 / 3001)$ \\
\hline Mortality without TBI & $9.1 \%(2 / 22)$ & $5 \%(2 / 40)$ & $10.9 \%(7 / 64)$ & $13.5 \%(18 / 133)$ & $16 \%(446 / 2792)$ \\
\hline
\end{tabular}

Children with coagulopathy (ChiCo) (INR $\geq 1.4$; PTT $\geq 40$; thrombocytes $\leq 100 \mathrm{k}$ ) according to age groups, hospital stay and mortality $I C U$ intensive care unit, TBI traumatic brain injury

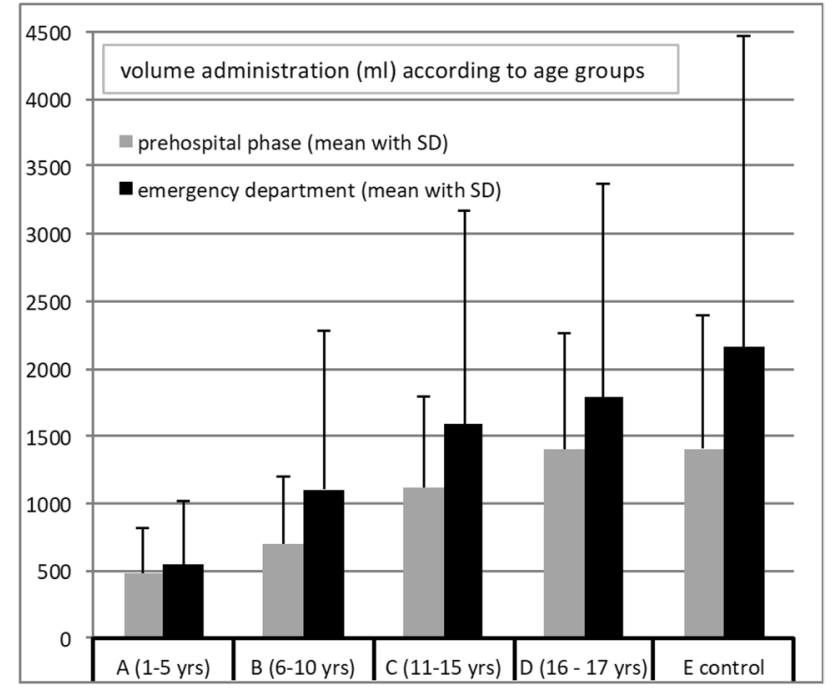

Fig. 2 Volume administration during prehospital resuscitation in ED (emergency department) depending on age groups

\section{Discussion}

The aim of this study was threefold: (1) to determine the mechanism of injury upon ER admission in traumatically injured children of different age groups, (2) to analyse frequency of coagulopathy and transfusion practice in those children when stratified according coagulopathy and (3) to analyse outcomes of these paediatric trauma patients.

Regarding the demographical results, the majority of the age groups of 16 and 17 years suffered traffic-related injuries during car or motorbike accidents which can be understood as a higher risk being involved in accidents shortly after the driving license was issued. With growing age, the percentage of male children suffering from

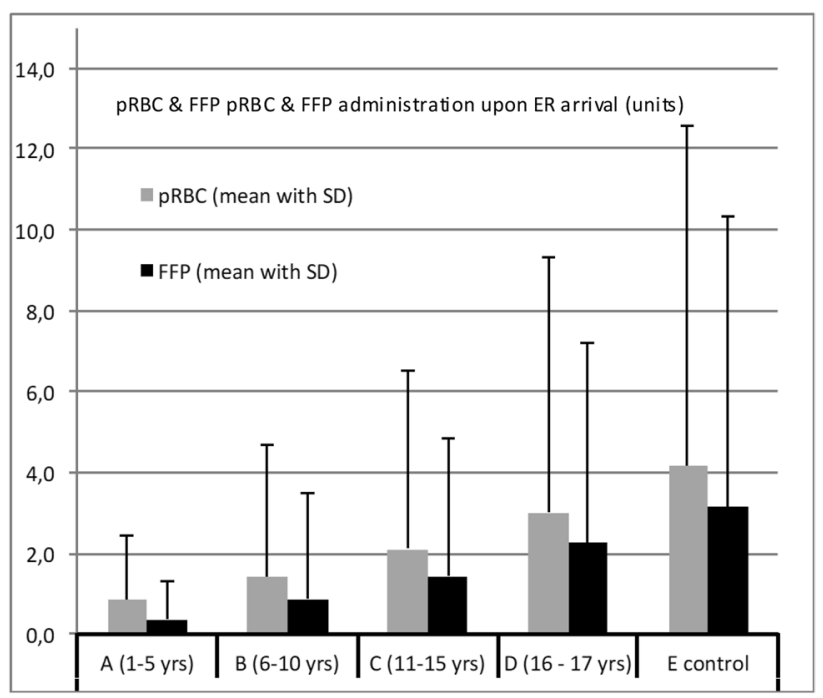

Fig. 3 Transfusion requirements for pRBCs (packed red blood cells) and FFP (fresh frozen plasma) until ICU (intensive care unit) admission during the prehospital resuscitation and in the ED (emergency department) according to different age groups

coagulopathy is increasing indicating a higher affinity of boys to risky recreational activities.

The data allow a distinction between car accidents as passenger of the vehicle and pedestrians. About one-third of children in groups A and B were injured as pedestrian. Remarkably high falls range from $9.6 \%(\mathrm{~B}, n=11)$ to $21 \%$ (A, $n=22$ ) and, therefore, are quite common in all age groups but with more than $1 / 5$ fatally among the youngest. Assuming these numbers are referring back to defenestration and falls from balcony, these events could easily be prevented by focused precautions.

As expected, relevant head injuries are decreasing with growing age; thoracic injuries and injuries of the extremities are increasing with growing age reflecting the importance 
of weight and surface of the head depending on age and upgrowth of children. Nevertheless, isolated brain trauma is more often in the youngest but still the commonest in combination with other injuries possibly explaining children's coagulopathy. In addition, lacerations at the head can cause relevant blood loss resulting in coagulopathy especially in the youngest.

Thus, irrespective of age, the majority of children in coagulopathy sustained a combination of brain trauma plus any other injury.

In this paediatric trauma population, which comprised 5351 injured children entered into the TR-DGU ${ }^{\circledR}$ in the period from 2009 to 2016, coagulopathy was present in $13.7 \%(n=733)$. Hendrickson and colleagues have evaluated coagulopathy also in a cohort of civilian paediatric trauma patients with $>80 \%$ blunt trauma [13]. In their single-centre cohort of 102 children (mean age 6 years; mean ISS 22 points), an abnormal prothrombin time was found in $72 \%$ while the PTT was abnormal in $38 \%$.

In a previous study, a frequency of $27 \%$ was reported from a cohort of children admitted to U.S. combat hospitals in Iraq and Afghanistan [17]. The majority of these children had sustained a penetrating trauma due to explosive devices (43\%) and gunshots (26\%), while children in the present study had mainly sustained a blunt trauma mechanism (>90\%) in all age groups. Taken together, both studies indicate that the frequency of trauma-associated coagulopathy and shock in children appears to be slightly lower compared to the adult trauma population where in both blunt and penetrating trauma patients coagulopathy is present in approximately one out of three trauma patients $[11,18]$. Further studies in adult trauma cohorts have reported even higher frequencies, but depending on definition and study design $[8,10,19]$.

The definition of shock used for adults within the TRDGU RRsyst $<90 \mathrm{mmHg}$ is not applicable in young children which is why shock as an outcome parameter could not be analysed in the present study. But literature, e.g. Patregnani et al. [17] reported $46 \%$ to be in severe shock and $38 \%$ being coagulopathic upon ER admission in their paediatric trauma cohort with an ISS $\geq 15$. In children with an ISS $<15$, coagulopathy and shock were only present in $20 \%$ and $33 \%$, respectively. The mean ISS in the study by Hendrickson et al. [20] was along with a higher frequency of abnormal standard coagulation parameters (PT, PTT, fibrinogen, haemoglobin, and platelet count) upon ER admission. The association between injury severity and coagulopathy is also well known in adult trauma population and trauma load has been identified as an important risk factor for coagulopathy and shock $[5,11,18,19,21]$.

As previously shown, the presence of coagulopathy and severe shock was also associated with increased overall mortality $[5,11,17,18]$. In the present study, one out of three children with coagulopathy died after admission. Several authors have previously identified coagulation abnormalities upon ER admission as an independent predictor of prognosis and mortality [22, 23]. Hendrickson et al. [13] reported abnormal prothrombin, partial thromboplastin times and platelet counts to be strongly associated with mortality in their cohort of severely blunt injured paediatric patients ( $p=0.005 ; p=0.001$, and $p<0.001$ ) remaining significant even after multivariate analysis and adjusting for injury severity (ISS). Furthermore, uncontrolled haemorrhage is considered to be responsible for approximately $50 \%$ of all trauma-related in-hospital deaths within the first $48 \mathrm{~h}$ of admission [3, 4], but heavily shifted towards the first $2 \mathrm{~h}$ $[24,25]$ emphasizing the importance of early recognition of coagulopathy and thus prompting early goal-directed therapy.

In paediatric trauma patients, special considerations have to be made regarding volume substitution. All estimates of blood volume, volume loss and replacement are based on weight with children over 3 months having an estimated blood volume of $70 \mathrm{ml} / \mathrm{kg}$ body weight and younger infants having an estimated $90 \mathrm{ml} / \mathrm{kg}$ body weight [26-28].

During pre- and early in-hospital care, patients in the state of severe shock and coagulopathy received increasing amounts of intravenous fluids. Iatrogenic dilution is often caused by unguided and over-administration of fluids in the acute phase of trauma care, and has been shown to interfere with coagulation and to diminish haemostasis $[7,8,19$, 29]. Furthermore, increasing frequency of coagulopathy and increasing levels of shock have been described in both paediatric and adult trauma populations $[8,11,17-19,30$, 31]. The presence of shock and the resulting hypoperfusion lead to acidemia which itself is another mechanism of inducing coagulopathy by interference with coagulation enzyme activity [8, 32-34]. Similar effects have been described in the presence of hypothermia $[8,19,33]$.

Besides the early recognition of coagulopathy and severe shock, early initiated goal-directed transfusion management is crucial $[35,36]$. In the present study, 30-40\% coagulopathic children received blood products independent of age. In general, pRBCs and FFPs were transfused at a 2 (or less): 1 ratio across all age subgroups. In the adult trauma population, high plasma to $\mathrm{pRBC}$ ratios have been shown to be associated with improved survival, primarily by decreasing death from haemorrhage both in military and civilian settings [37, 38].

Interestingly, a retrospective study of patients receiving FFP alone compared to patients receiving coagulation factor concentrates without FFP showed the patients receiving FFP alone had an increased frequency of multi-organ failure [39].

However, the implementation of a massive transfusion protocol with a fixed 1:1 ratio did not improve overall mortality in a small under-powered single-centre cohort of 
paediatric patients [20]. However, MT occurs less common in children due to their greater physiological reserve and tolerance to blood loss. Due to varying body volumes by age, gender and weight, defining clear criteria for MT in children is difficult. Chidester and colleagues observed in their single-centre study that mortality was not significantly different between children who received massive transfusion protocol and children who were given blood at the physician's discretion [40].

Larger studies are essential to determine the potential benefit of this approach, which has been observed frequently in adult trauma patients. Moreover, the implementation of management and transfusion guidelines comparable to current guidelines for adult trauma patients is also needed for the paediatric population [41].

Certain limitations of this investigation have to be acknowledged. This is a retrospective study with all the associated shortcomings, for example, the introduction of a selection bias. Furthermore, a significant number of children had to be excluded from the present analysis, either due to missing INR and Quick's value or secondary admission. Furthermore, hypothermia has been shown to be an important trigger of coagulopathy $[8,19,25]$. Unfortunately, body temperature is only poorly documented in the TR-DGU ${ }^{\circledR}$ and, therefore, the role of hypothermia could not be substantiated in the present analysis. Additionally, the vast majority of our patients suffered from blunt trauma, as penetrating trauma is rare (less than 10\%) in German trauma populations. Further prospective trials are needed to gain knowledge on the physiology and pathophysiology of severe shock and coagulopathy in paediatric trauma patients. Additional studies are required to determine if damage control resuscitation strategies improve survival in paediatric populations.

\section{Conclusion}

The frequency of coagulopathy upon ER admission in the paediatric trauma population was $13.7 \%$. Blood products (pRBC and FFP) were transfused in a close to 2:1 ratio across all age subgroups. One-third or more (group A) of coagulopathic children died after hospital admission across all age subgroups. Depending on the injury pattern, mortality with TBI only was the highest. Prospective studies are warranted to determine if early and more aggressive coagulation management including factor replacement and the implementation of (massive) transfusion protocols (MTPs) may improve outcomes in this population.

Acknowledgements Open Access funding provided by Projekt DEAL. We would like to thank the TR-DGU and the AUC staff for crucial help and support. Furthermore, the authors would like to thank all active centres and participants of the TR-DGU ${ }^{\circledR}$ for data entry into the registry. For an overview of all active centres, please see https://www. traumaregister-dgu.de/.

Author contributions $\mathrm{AD}, \mathrm{AW}, \mathrm{FM}$ and FM performed the literature review and wrote the manuscript; DA, MM, MM, FM and RL provided scientific support and valuable advice working on the manuscript; AD, AW,FM, RL, MM and MM helped in analysing and interpreting the literature and data; DA, MF, RL, AD and MM proofread the manuscript, revised it critically and provided generous technical support with figures and tables. All authors have read and approved the final manuscript.

Funding This research received no specific grant from any funding agency in the public commercial or not-for-profit sectors. There are no special funding sources, financial or non-financial conflicts, interests or acknowledgments to be declared regarding this manuscript.

Availability of data and materials All data analysed for this study are managed by the TraumaRegister-DGU ${ }^{\circledR}$. The scientific steering group is the Committee on Emergency Medicine, Intensive Care and Trauma Management of the German Trauma Society (Sektion NIS). Data analysis is approved according to a peer-review procedure established by Sektion NIS. Please find more information https://www.traumaregi ster-dgu.de. TraumaRegister-DGU ${ }^{\circledR}$ is setting global standards for the quality management of severely injured. Almost 700 hospitals from 9 different countries are participating. Mostly the participating hospitals are located in Germany, but other countries such as Belgium, Finland, Luxembourg, the Netherlands, Austria, Switzerland, Slovenia and United Arab Emirates are contributing increasingly. Since its founding in 1993, data from more than 270,000 cases have been documented. In 2017 alone, about 35,000 cases have been entered in TraumaRegister$\mathrm{DGU}^{\circledR}$. For the hospitals, TraumaRegister-DGU ${ }^{\circledR}$ is not only an instrument for external quality assurance, but has also provided a basis for clinical and healthcare research for years.

\section{Compliance with ethical standards}

Conflict of interest The authors state that this manuscript has not been published previously and that there is no consideration for publication elsewhere. The authors declare that they have no competing interests.

Ethics approval The present study is in line with the publication guidelines of the TraumaRegister-DGU ${ }^{\circledR}$ and is registered as TR-DGU project ID 2018-005. All methods were carried out in accordance with relevant guidelines and regulations. More information can be found online on https://www.traumaregister-dgu.de.

Consent to participate The entry and the analysis of data are pseudonymised; therefore, no special consent had to be obtained. Please see the guidelines of the TR-DGU for further information. The presented work is based on routinely documented data used for an initiative for external quality control. External quality control is a legal requirement for hospitals. Since only routinely available data were used, no informed consent was required. Institutional and demographic details were removed from the scientific dataset so that a re-identification of individual cases was impossible.

Consent to publish All authors have read and approved the final manuscript.

Open Access This article is licensed under a Creative Commons Attribution 4.0 International License, which permits use, sharing, adaptation, distribution and reproduction in any medium or format, as long as you give appropriate credit to the original author(s) and the source, 
provide a link to the Creative Commons licence, and indicate if changes were made. The images or other third party material in this article are included in the article's Creative Commons licence, unless indicated otherwise in a credit line to the material. If material is not included in the article's Creative Commons licence and your intended use is not permitted by statutory regulation or exceeds the permitted use, you will need to obtain permission directly from the copyright holder. To view a copy of this licence, visit http://creativecommons.org/licenses/by/4.0/.

\section{References}

1. Krug EG, Sharma GK, Lozano R. The global burden of injuries. Am J Public Health. 2000;90:523-6.

2. Murray CJ, Lopez AD. Mortality by cause for eight regions of the world: Global Burden of Disease Study. Lancet. 1997;349:1269-76.

3. Sauaia A, Moore FA, Moore EE, Moser KS, Brennan R, Read RA, et al. Epidemiology of trauma deaths: a reassessment. J Trauma. 1995;38:185-93.

4. Evans JA, Van Wessem KJP, McDougall D, Lee KA, Lyons T, Balogh ZJ. Epidemiology of traumatic deaths: comprehensive population-based assessment. World J Surg. 2010;34:158-63.

5. Brohi K, Singh J, Heron M, Coats T. Acute traumatic coagulopathy. J Trauma. 2003;54:1127-30.

6. Maegele M, Paffrath T, Bouillon B. Acute traumatic coagulopathy in severe injury. Dtsch Arztebl Int. 2011;108:827-35.

7. Maegele M. Frequency, risk stratification and therapeutic management of acute post-traumatic coagulopathy. Vox Sang. 2009;97:39-49.

8. Hess JR, Brohi K, Dutton RP, Hauser CJ, Holcomb JB, Kluger Y, et al. The coagulopathy of trauma: a review of mechanisms. J Trauma. 2008;65:748-54.

9. Brohi K, Cohen MJ, Ganter MT, Matthay MA, Mackersie RC, Pittet J-F. Acute traumatic coagulopathy: initiated by hypoperfusion: modulated through the protein C pathway? Ann Surg. 2007;245:812-8.

10. Floccard B, Rugeri L, Faure A, Saint Denis M, Boyle EM, Peguet $\mathrm{O}$, et al. Early coagulopathy in trauma patients: an on-scene and hospital admission study. Injury. 2012;43:26-322.

11. Maegele M, Lefering R, Yucel N, Tjardes T, Rixen D, Paffrath $\mathrm{T}$, et al. Early coagulopathy in multiple injury: an analysis from the German Trauma Registry on 8724 patients. Injury. 2007;38:298-304.

12. Vincent JL, De Mendonça A, Cantraine F, Moreno R, Takala J, Suter PM, et al. Use of the SOFA score to assess the incidence of organ dysfunction/failure in intensive care units: results of a multicenter, prospective study. Crit Care Med. 1998;26:1793-800.

13. Hendrickson JE, Shaz BH, Pereira G, Atkins E, Johnson KK, Bao $\mathrm{G}$, et al. Coagulopathy is prevalent and associated with adverse outcomes in transfused pediatric trauma patients. J Pediatr. 2012;160:204.

14. Trauma Register of the German Society of Trauma Surgery. Scoring study committee of the German Society of Trauma Surgery. Unfallchirurgie. 1994;97:230-7.

15. Greenspan L, McLellan B, Greig H. Abbreviated Injury Scale and Injury Severity Score: a scoring chart. J Trauma. 1985;25:60-4.

16. Thomas L. Labor und diagnose: Indikation und Bewertung von Laborbefunden für die medizinische Diagnostik. 5. erweite. Frankfurt: TH-Books Verlagsgesellschaft; 2000.

17. Patregnani JT, Borgman MA, Maegele M, Wade CE, Blackbourne LH, Spinella PC. Coagulopathy and shock on admission is associated with mortality for children with traumatic injuries at combat support hospitals. Pediatr Crit Care Med. 2012;13:273-7.

18. Niles SE, McLaughlin DF, Perkins JG, Wade CE, Li Y, Spinella $\mathrm{PC}$, et al. Increased mortality associated with the early coagulopathy of trauma in combat casualties. J Trauma. 2008;64:1459-63 (discussion 1463-5).

19. Wafaisade A, Wutzler S, Lefering R, Tjardes T, Banerjee M, Paffrath T, et al. Drivers of acute coagulopathy after severe trauma: a multivariate analysis of 1987 patients. Emerg Med J. 2010;27:934-9.

20. Hendrickson JE, Shaz BH, Pereira G, Parker PM, Jessup P, Atwell $\mathrm{F}$, et al. Implementation of a pediatric trauma massive transfusion protocol: one institution's experience. Transfusion. 2012;52:1228-366.

21. Cosgriff N, Moore EE, Sauaia A, Kenny-Moynihan M, Burch JM, Galloway B. Predicting life-threatening coagulopathy in the massively transfused trauma patient: hypothermia and acidoses revisited. J Trauma. 1997;42:857-61 (discussion 861-2).

22. MacLeod JBA, Lynn M, McKenney MG, Cohn SM, Murtha M. Early coagulopathy predicts mortality in trauma. J Trauma Inj Infect Crit Care. 2003;55:39-44.

23. Reed CR, Williamson H, Vatsaas C, Kamyszek R, Leraas HJ, Ray $\mathrm{C}$, et al. Higher mortality in pediatric and adult trauma patients with traumatic coagulopathy, using age-adjusted diagnostic criteria. Surgery [Internet]. 2019 [cited 2019 Oct 20];165:1108-15. https://www.ncbi.nlm.nih.gov/pubmed/31027837

24. MacLeod JBA, Cohn SM, Johnson EW, McKenney MG. Trauma deaths in the first hour: are they all unsalvageable injuries? Am J Surg. 2007;193:195-9.

25. Peng R, Chang C, Gilmore D, Bongard F. Epidemiology of immediate and early trauma deaths at an urban level I trauma center. Am J Surg. 1998;64:950-4.

26. Nystrup KB, Stensballe J, Bøttger M, Johansson PI, Ostrowski SR. Transfusion therapy in paediatric trauma patients: a review of the literature. Scand J Traum Resusc Emerg Med. 2015;23:21.

27. Dehmer JJ, Adamson WT. Massive transfusion and blood product use in the pediatric trauma patient. Semin Pediatr Surg. 2010;19:286-91.

28. Barcelona SL, Thompson AA, Cote CJ. Intraoperative pediatric blood transfusion therapy: a review of common issues. Part II: transfusion therapy, special considerations, and reduction of allogenic blood transfusions. Pediatr Anesth. 2005;15:814-30.

29. Driessen A, Fröhlich M, Schäfer N, Mutschler M, Defosse JM, Brockamp T, et al. Prehospital volume resuscitation-did evidence defeat the crystalloid dogma? An analysis of the TraumaRegister DGU ${ }^{\circledR}$ 2002-2012. Scand J Trauma Resusc Emerg Med. 2016;24:42.

30. Schäfer N, Driessen A, Fröhlich M, Stürmer EK, Maegele M. Diversity in clinical management and protocols for the treatment of major bleeding trauma patients across European level I Trauma Centres. Scand J Trauma Resusc Emerg Med. 2015;23:74.

31. Mutschler M, Hoffmann M, Wölfl C, Münzberg M, Schipper I, Paffrath T, et al. Is the ATLS classification of hypovolaemic shock appreciated in daily trauma care? An online-survey among 383 ATLS course directors and instructors. Emerg Med J. 2013;32:134.

32. Wolberg AS, Meng ZH, Monroe DM, Hoffman M. A systematic evaluation of the effect of temperature on coagulation enzyme activity and platelet function. J Trauma. 2004;56:1221-8.

33. Meng ZH, Wolberg AS, Monroe DM, Hoffman M. The effect of temperature and $\mathrm{pH}$ on the activity of factor VIIa: implications for the efficacy of high-dose factor VIIa in hypothermic and acidotic patients. J Trauma. 2003;55:886-91.

34. Driessen A, Maegele M. Traumaassoziierte Gerinnungsstörungr. Notfall Rettungsmedizin. 2015;18:1-7. 
35. Sperry JL, Ochoa JB, Gunn SR, Alarcon LH, Minei JP, Cuschieri $\mathrm{J}$, et al. An FFP: PRBC transfusion ratio $\geq 1: 15$ is associated with a lower risk of mortality after massive transfusion. J Trauma Inj Infect Crit Care. 2008;65:986-93.

36. Driessen A, Schäfer N, Albrecht V, Schenk M, Fröhlich M, Stürmer EK (2015) An Infrastructure and clinical practice for the detection and management of trauma-associated haemorrhage and coagulopathy. Eur J Trauma Emerg Surg 41:413

37. Borgman MA, Spinella PC, Perkins JG, Grathwohl KW, Repine T, Beekley AC, et al. The ratio of blood products transfused affects mortality in patients receiving massive transfusions at a combat support hospital. J Trauma Inj Infect Crit Care. 2007;63:805-13.

38. Maegele M, Lefering R, Paffrath T, Tjardes T, Simanski C, Bouillon B. Red-blood-cell to plasma ratios transfused during massive transfusion are associated with mortality in severe multiple injury: a retrospective analysis from the Trauma Registry of the Deutsche Gesellschaft für Unfallchirurgie. Vox Sang. 2008;95:112-9.

39. Christiaans SC, Duhachek-Stapelman AL, Russell RT, Lisco SJ, Kerby JD, Pittet J-F. Coagulopathy after severe pediatric trauma. Shock [Internet]. 2014 [cited 2019 Oct 20];41:476-90. https:// www.ncbi.nlm.nih.gov/pubmed/24569507.

40. Chidester SJ, Williams N, Wang W, Groner JI. A pediatric massive transfusion protocol. J Trauma Acute Care Surg. [Internet]. 2012 [cited 2019 Oct 20];73:1273-7. https://www.ncbi.nlm.nih. gov/pubmed/23064608.

41. Neugebauer EAM, Waydhas C, Lendemans S, Rixen D, Eikermann M, Pohlemann T. The treatment of patients with severe and multiple traumatic injuries. Dtsch Arztebl Int. 2012;109:102-8. 